\title{
Suppression of transgene RNA silencing in transgenic Arabidopsis thaliana by a mild strain of Cucumber mosaic virus
}

\author{
Ken Nomura • Hidetoshi Uekusa $\cdot$ Nobuhiro Kita
}

Received: 12 July 2013/ Accepted: 10 March 2014/Published online: 2 July 2014

(C) The Author(s) 2014. This article is published with open access at Springerlink.com

\begin{abstract}
The ability of Cucumber mosaic virus (CMV) subgroup II strain CMV-KT to suppress RNA silencing via posttranscriptional gene silencing (PTGS) was determined using Turnip mosaic virus (TuMV)-resistant transgenic Arabidopsis thaliana (TuR-At) carrying TuMV coat protein (CP) transgenes. CMV-KT induced only slight growth retardation in TuR-At plants, but no dwarf or mosaic symptoms, while subgroup I strain Y (CMV-Y) caused severe symptoms. Expression of the RNA-silenced TuMV$\mathrm{CP}$ transgene resumed and produced TuMV-CP in either CMV-KT- or CMV-Y-infected TuR-At plants, indicating that the RNA silencing of the TuMV-CP gene was suppressed. Challenge inoculation experiments revealed that RNA silencing of the TuMV-CP transgene by CMV-KT infection is suppressed mostly in young developing leaves, but not in mature leaves, of TuR-At plants. These results demonstrated that transgene-derived virus resistance in transgenic Arabidopsis plants can be compromised by even a mild strain of CMV infection.
\end{abstract}

Keywords RNA silencing - Suppressor - Cucumber mosaic virus . Turnip mosaic virus . Virus resistance

\section{Introduction}

Cucumber mosaic virus (CMV), the type species of genus Cucumovirus, consists of three genomic RNAs of different sizes (RNA1, RNA2, and RNA3) with two subgenomic

K. Nomura $(\bowtie) \cdot$ H. Uekusa $\cdot$ N. Kita Division of Agricultural Production Technology Science, Kanagawa Agricultural Technology Center, 1617 Kamikisawa, Hiratsuka, Kanagawa 259-1204, Japan

e-mail: nomura.a521@ pref.kanagawa.jp
RNAs (RNA4 and RNA4A) and is classified into one of three subgroups (IA, IB, or II) based on sequence homology (Palukaitis and García-Arenal. 2003; Roossinck et al. 1999). Some CMV strains carry an additional low molecular-weight satellite RNA that affects the expression of symptoms to various degrees (Devic et al. 1989; Gonsalves et al. 1982). Mutations within the viral coat protein (CP) or $2 \mathrm{~b}$ protein gene(s) resulting in amino-acid substitutions also affect symptom development and disease severity (Shintaku et al. 1992; Suzuki et al. 1995). CMV-2b protein, which is involved in the long-distance movement and pathogenicity of the virus, functions as an RNA silencing suppressor (RSS) (Ding et al. 1994, 1995; Lewsey et al. 2009; Shi et al. 2002, 2003; Soards et al. 2002; Zhang et al. 2006). It suppresses RNA silencing via binding to Argonaute 1 and targeting small RNAs; the ability of $2 b$ to bind small RNAs is critical for RSS activity (González et al. 2010; Goto et al. 2007). In addition to the RSS activity identified for the CMV $2 b$ protein, RSS has been identified for proteins from various plant pathogenic viruses such as the HC-Pro from Potyvirus, the P25 protein from Potexvirus, and the P19 protein from Tombusvirus, all of which possess species-specific mechanisms of suppression (Anandalakshmi et al. 1998; Brigneti et al. 1998; Vargason et al. 2003; Voinnet et al. 2000).

The fact that plant viruses possess RSS implies that resistance to a specific virus via RNA silencing of the transgene would be lost when transgenic plants were coinfected with other viruses that also exhibit RSS. Actually, Savenkov and Valkonen (2001) reported that Potato virus $Y$ (PVY) infection breaks down the Potato virus A resistance of transgenic Nicotiana benthamiana plants carrying the CP transgene. For PVY-resistant transgenic tobacco plants carrying the nuclear inclusion a (NIa) transgene, Mitter et al. (2003) showed that PVY resumed infectivity 
when the transgenic tobacco plants were pre-infected by a severe strain of CMV. The ability of a CMV severe strain to break down the transgenic resistance to a virus was also demonstrated in transgenic Plum pox virus (PPV)-resistant $N$. benthamiana plants containing the $5^{\prime}$-region of the NIa gene, while Tobacco vein mottling virus (TVMV) could not (Simón-Mateo et al. 2003). However, whether mild CMV strains can suppress the RNA silencing and whether the virulence level affects the efficiency of RNA silencing has not been determined.

Previously, we reported that transgenic Arabidopsis thaliana carrying the full coding region of a Turnip mosaic virus (TuMV)-CP gene showed complete resistance to TuMV isolates (Nomura et al. 2004). The purpose of the present study was to determine the RNA silencing suppression ability of a mild strain of CMV isolated from tomato using TuMV-resistant transgenic $A$. thaliana plants (TuR-At) carrying posttranscriptionally silenced TuMV$\mathrm{CP}$ transgenes.

\section{Materials and methods}

\section{Arabidopsis lines and viral strains}

Three TuR-At Arabidopsis lines, CP112-R1, CP202-R1, and CP232-R1, carrying TuMV-CP transgenes with posttranscriptionally silenced expression, and a TuMV strain, TuMV-JO, were described previously (Nomura et al. 2004). Nontransgenic wild-type Col-0 of Arabidopsis thaliana was used as the control in these experiments. Mild strain CMV-KT and severe strain CMV-Y were used as counter viruses (Nomura et al. 2012; Suzuki et al. 1991).

\section{Western blot analysis}

Leaves (ca. $50 \mathrm{mg}$ ) were harvested and prepared for western blotting using TuMV-CP or CMV-CP rabbit polyclonal antiserum as described previously (Nomura et al. 2004).

Response of TuMV-resistant transgenic Arabidopsis plants to TuMV after CMV-KT pre-inoculation

Viral inoculum was prepared by grinding $N$. tabacum (tobacco) or $N$. benthamiana leaves infected either with CMV-KT or TuMV-JO in $0.1 \mathrm{M}$ phosphate buffer $(\mathrm{pH}$ 7.0). When A. thaliana plants bore 10 fully expanded leaves, CMV-KT was inoculated as the first virus by rubbing the inoculum onto three fully expanded mature leaves. Plants were then kept in a growth chamber at $22{ }^{\circ} \mathrm{C}$ with $12 \mathrm{~h}$ light/ $12 \mathrm{~h}$ dark. 1 week after inoculation, establishment of CMV-KT infection in the inoculated plants was confirmed by western blot using rabbit polyclonal antiCMV serum. For challenge inoculation tests, TuMV-JO was used to inoculate either three mature leaves 7 days later or three newly emerged developing leaves 14 days after the CMV-KT pre-inoculation. In both cases, establishment of TuMV infection in these challenge-inoculated transgenic plants was determined by RT-PCR 2 weeks after the challenge inoculation. Because the TuMV-inoculated transgenic plants contain TuMV-CP transgenes, RTPCR was performed by targeting the nuclear inclusion $b$ (NIb) gene of TuMV instead of the TuMV-CP transgene to specifically detect TuMV. A forward primer (NIbF1: 5'GGAAACAATAGCGGACAGC- $3^{\prime}$ ) and reverse primer (NIbR1: 5'-CTGGTGATAAACACAAGCTT- $3^{\prime}$ ) were used with the RNA LA PCR Kit (Takara Bio, Otsu, Shiga, Japan) according to the manufacturer's instructions to amplify a 632-bp DNA fragment within the NIb gene. Amplified DNA fragments were separated by $1 \%(w / v)$ agarose gel electrophoresis and cloned into the pT7 Blue vector (Novagen, Madison, WI, USA).

Sequencing analysis of the $2 \mathrm{~b}$ gene of CMV-KT

A conserved region of $817 \mathrm{bp}$ within the RNA2 genome of CMV-KT was cloned from total RNA extracted from CMV-KT-infected tobacco leaves by RT-PCR using the RNA LA PCR Kit (Takara Bio) with forward primer CMV.RNA2F1 (5'-TCGAGTTGAAATACAAGAAG-3') and reverse primer CMV.RNA2R1 (5'-TGGTCTCC TTATGGAGAACC- $3^{\prime}$ ) according to the manufacturer's instructions. Amplified DNA fragments were separated by $1 \%(\mathrm{w} / \mathrm{v})$ agarose gel electrophoresis and cloned into the pT7 Blue Vector (Novagen) for cycle sequencing using an automated 3130 DNA sequencer (Applied Biosystems, Foster City, CA, USA) according to the manufacturer's instructions.

\section{Results}

Suppression of RNA silencing by a mild strain of CMV in transgenic Arabidopsis plants

In nontransgenic Arabidopsis plants, CMV-KT, a mild strain of CMV, induced slight growth retardation but not dwarfing or mosaic symptoms; however, CMV-Y, a severe strain, caused distinct dwarfing and mosaic, as described previously (Nomura et al. 2012). Although both CMV-Y and CMV-KT multiplied in all plants of three TuR-Attransgenic lines, CP112-R1, CP202-R1, and CP232-R1, as confirmed by western blot, the level of accumulation was higher in plants inoculated with CMV-Y than in those inoculated with CMV-KT (Fig. 1a). When the same line of 


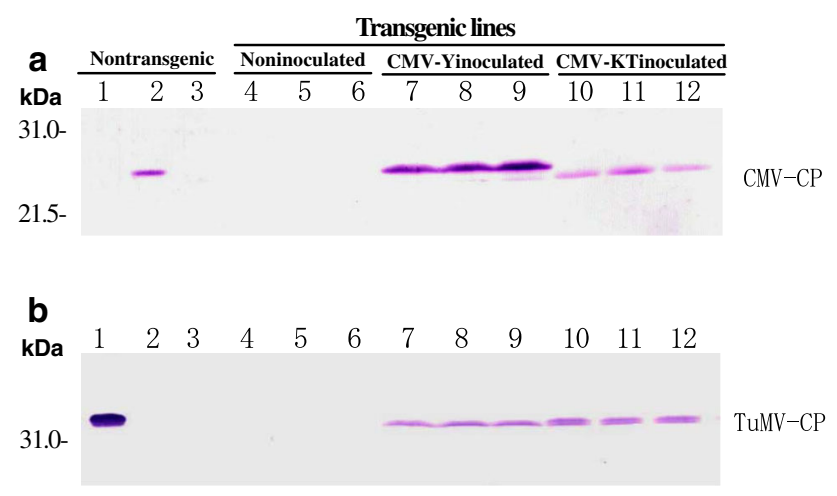

Fig. 1 Response of Turnip mosaic virus (TuMV)-resistant transgenic Arabidopsis thaliana plants, carrying the coat protein (CP) gene of TuMV to inoculation with Cucumber mosaic virus (CMV). a Detection of inoculated CMV by western blot using rabbit antiserum against CMV-CP; $\mathbf{b}$ detection of TuMV-CP derived from the TuMV$\mathrm{CP}$ transgene by western blot using rabbit antiserum against TuMVCP. Nontransgenic, wild-type A. thaliana plants (Col-0) inoculated with either a severe CMV strain (CMV-Y) or TuMV were used as the controls. Transgenic A. thaliana plants containing posttranscriptionally RNA-silenced TuMV-CP gene(s). Lane 1 Col-0 infected with TuMV, lane 2 Col-0 infected with CMV-Y, lane 3 noninfected Col-0, lanes 4-6 transgenic lines (listed below) without CMV inoculation, lanes 7-9 transgenic lines inoculated with CMV-Y, lanes 10-12 transgenic lines inoculated with CMV-KT. Transgenic lines are CP112-R1 (in lanes 4, 7, and 10), CP202-R1 (in lanes 5, 8, and 11) and CP232-R1 (lanes 6, 9, and 12)

Arabidopsis plants was pre-inoculated with either CMV-Y or CMV-KT, TuMV-CP was detected by western blot in all of the TuR-At and wild-type plants that had been preinoculated with CMV, while no signal was detected in any of the plants that had not been inoculated with CMV (Fig. 1b). Interestingly, TuMV CP accumulation levels differed depending on the tissue: TuMV CP was not detected in the CMV-pre-inoculated leaves or in mature leaves, but was detected at conspicuously high levels in the developing leaves and bolting shoots (data not shown). These results demonstrated that the RSS activity of CMV was high in developing leaves and bolting shoots and that mild strains of CMV can also suppress the RNA silencing of TuMV-CP transgenes in all of these TuR-At lines.

\section{Response to TuMV infection in transgenic Arabidopsis plants pre-inoculated with CMV}

To determine the effects of pre-inoculation with CMV-KT on the response of TuR-At to TuMV infection, the mature leaves of TuR-At plants were first inoculated with CMV$\mathrm{KT}$, and then their developing leaves were challengeinoculated with TuMV at 14 days after the pre-inoculation. As a result, $40-60 \%$ of the TuR-At plants lost their TuMV resistance and began to show not only growth retardation, but also typical viral symptoms comparable to those that

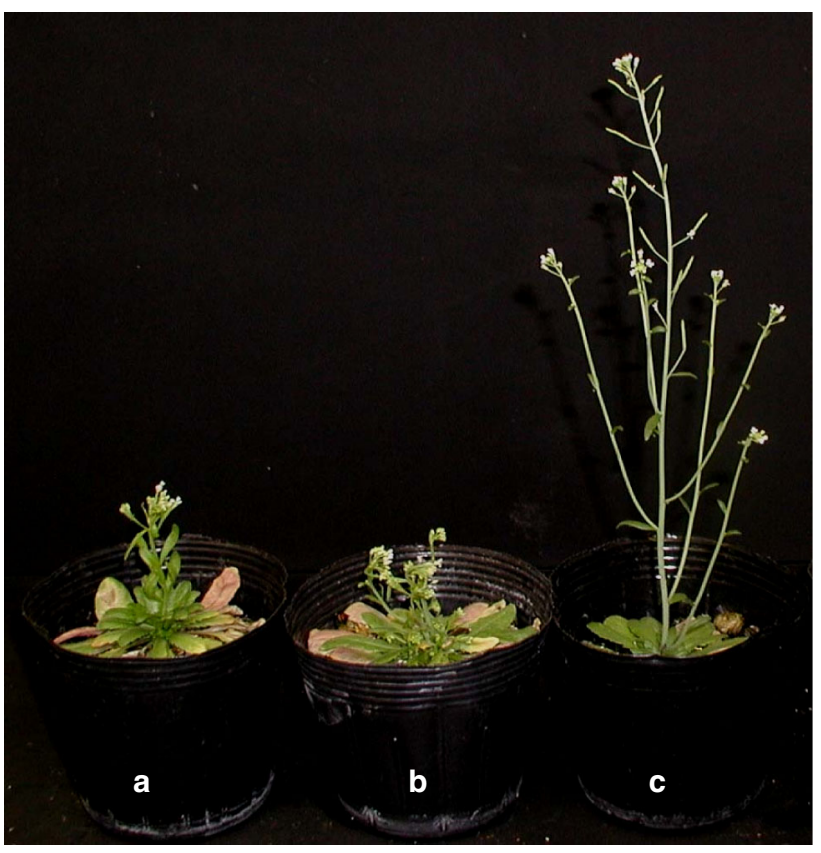

Fig. 2 Differential response of an Arabidopsis thaliana wild-type plant and Turnip mosaic virus (TuMV)-resistant transgenic plants to TuMV infection. a A Col-0 plant inoculated with TuMV only; b CP112-R1 pre-inoculated with a mild strain of Cucumber mosaic virus (CMV)-KT onto mature leaves, followed by challenge inoculation with TuMV at 14 days after CMV-KT pre-inoculation; c CP112-R1 pre-inoculated with CMV-KT, followed by challenge inoculation with TuMV of mature leaves at 7 days after CMV-KT pre-inoculation

occur in nontransgenic, wild-type plants (Fig. 2a, b; Table 1). In contrast, when mature leaves were inoculated with TuMV at 7 days after CMV-KT pre-inoculation, TuMV resistance was maintained, and plants exhibited normal growth (Fig. 2c). RT-PCR detection of TuMV in the TuR-At plants pre-inoculated with CMV-KT also confirmed that TuMV had multiplied in plants that had been challenge-inoculated with TuMV on developing leaves, whereas no TuMV CP was detected in plants that had been challenge-inoculated with TuMV on mature leaves (Fig. 3). Therefore, these results demonstrate that suppression of RNA silencing of the TuMV-CP transgene by CMV-KT infection mostly occurs in the young developing leaves, but not in the mature leaves of TuR-At plants.

\section{Sequence analysis of the CMV $2 \mathrm{~b}$ gene}

After establishing that both CMV-KT and CMV-Y used in the present study could suppress RNA silencing in TuR-AT plants regardless of differences in their pathogenicity, we then determined the sequence of the CMV-KT $2 b$ protein gene (GenBank/EMBL/DDBJ database accession: AB709965), which plays a major role in RNA silencing suppression, for comparison among various CMV strains. 
Table 1 Differential responses of Turnip mosaic virus (TuMV)-resistant transgenic Arabidopsis thaliana plants to challenge inoculation with TuMV after pre-inoculation with a mild strain of Cucumber mosaic virus (CMV)-KT of either developing or mature leaves

\begin{tabular}{|c|c|c|c|c|c|}
\hline \multirow[t]{2}{*}{ Leaf type ${ }^{a}$ pre-inoculated } & \multirow[t]{2}{*}{ Arabidopsis line ${ }^{\mathrm{b}}$} & \multicolumn{3}{|c|}{ No. of plants with TuMV } & \multirow[t]{2}{*}{ Infection rate $(\%)$} \\
\hline & & Inoculated & Infected & Detected & \\
\hline \multirow[t]{4}{*}{ Immature } & CP112-R1 & 20 & 8 & 8 & 40 \\
\hline & CP202-R1 & 20 & 12 & 12 & \\
\hline & CP232-R1 & 20 & 12 & 12 & 60 \\
\hline & Col-0 & 10 & 10 & 10 & 100 \\
\hline \multirow[t]{4}{*}{ Mature } & CP112-R1 & 20 & 0 & 0 & 0 \\
\hline & CP202-R1 & 20 & 0 & 0 & 0 \\
\hline & CP232-R1 & 20 & 0 & 0 & 0 \\
\hline & Col- 0 & 10 & 10 & 10 & 100 \\
\hline
\end{tabular}

a $\mathrm{CMV}$ was used to rub-inoculate 3 mature leaves of plants at the 10 -leaf growth stage, which were kept in a growth chamber at $22{ }^{\circ} \mathrm{C}$ with $12 \mathrm{~h}$ light/12 h dark until challenge inoculation with TuMV

b Wild type (Col-0)-derived, TuMV-resistant, transgenic A. thaliana lines that contain a transcriptionally RNA-silenced TuMV-coat protein (CP) transgene

c TuMV was used to challenge-inoculate either immature at 7 days or mature leaves at 14 days, after pre-inoculation with mild strain CMV-KT. Viral infection was confirmed by growth retardation, mosaic symptom on leaves, or both. TuMV multiplication was confirmed by RT-PCR using a specific primer pair to amplify the conserved region of the nuclear inclusion $b(\mathrm{NIb})$ gene of TuMV
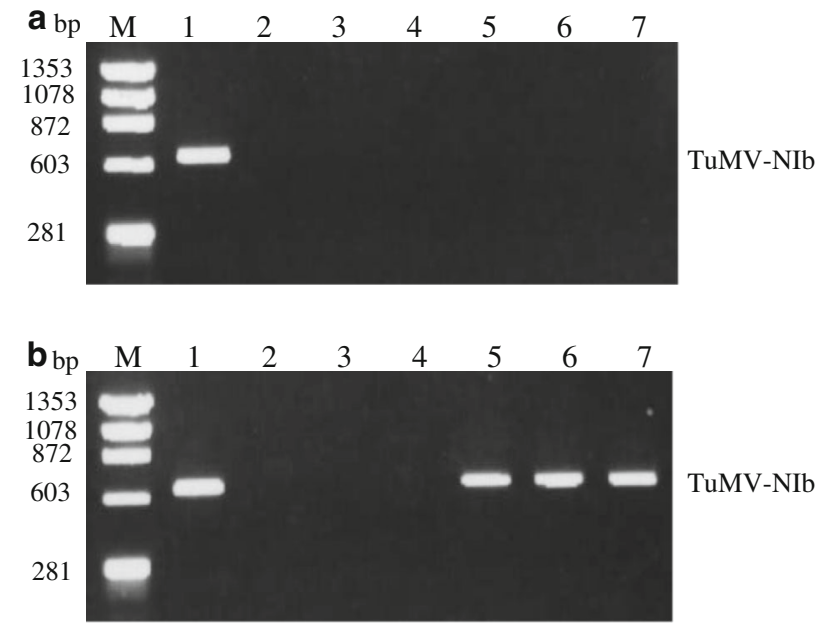

Fig. 3 Detection of challenge-inoculated Turnip mosaic virus (TuMV) by RT-PCR in TuMV-resistant transgenic Arabidopsis thaliana plants carrying TuMV-coat protein transgenes after preinoculation with a mild strain of Cucumber mosaic virus (CMV)-KT of mature (a) or developing (b) leaves at 7 or 14 days after preinoculation, respectively. Lane 1 TuMV inoculated nontransgenic Col-0; lanes 2-4 noninoculated transgenic lines without CMV preinoculation; lanes 5-7 TuMV-challenge-inoculated transgenic lines after pre-inoculation with CMV-KT. Transgenic lines are CP112-R1 (lanes 2 and 5), CP202-R1 (lanes 3 and 6 ) and CP232-R1 (lanes 4 and 7). RT-PCR was performed using a specific primer pair that can amplify the conserved region of nuclear inclusion $b(\mathrm{NIb})$ gene of TuMV

Homology analysis of the $2 \mathrm{~b}$ genes demonstrated that CMV-KT shares 98.3 and $99.0 \%$ homology with subgroup II strains CMV-Q and CMV-TN, respectively, but shares only 62.0 and $65.0 \%$ homology with subgroup I severe strains CMV-Y and CMV-O, respectively. When the $2 \mathrm{~b}$ sequence of CMV-KT was compared with that of CMV-Q in subgroup II, there were four single-base differences within the $2 \mathrm{~b}$ protein gene and two of these four base changes were predicted to correspond to the amino acid substitution, $\mathrm{L} 17 \mathrm{H}$ and $\mathrm{I} 51 \mathrm{~F}$, while the remaining two were silent mutations. Two single-base changes in $2 \mathrm{~b}$ protein gene were also found when comparing the $2 b$ sequence of CMV-KT with CMV-TN, but both were silent mutations.

\section{Discussion}

This study demonstrated that CMV-KT, a mild strain of CMV, can suppress the posttranscriptional RNA silencing of a transgene that confers TuMV resistance to transgenic Arabidopsis plants, allowing subsequent TuMV infection in the developing leaves. Under natural conditions, synergetic effects are often observed in various plant-virus interactions, including mixed infection by CMV and potyviruses. In radish, severe mosaic symptoms are induced synergistically by mixed infection of CMV and TuMV, although infection solely by CMV induces no symptoms in infected plants (Sano and Kojima 1989). CMV can also affect the host's innate metabolism and enhance disease severity after simultaneous infection of plants with potyviruses (Wang et al. 2002). In some cases, proteins that suppress RNA silencing mediate the synergistic interactions (Brigneti et al. 1998). Siddiqui et al. (2011) reported that a mild strain, CMV-Kin, enhances symptom development of tobacco plants infected by TMV. In this case, only the $2 \mathrm{~b}$ protein of $\mathrm{CMV}$ is needed for this synergistic 
relationship. The present study suggests that pre-inoculation with a mild strain of CMV-KT allows TuMV to infect TuR-At plants by suppressing RNA silencing of the TuMV-CP transgene, probably via synergetic interaction with the CMV 2b protein.

The $2 b$ protein of CMV was initially identified as a factor in two functions, viral movement and pathogenicity determination, and later as a factor in RSS (Brigneti et al. 1998; Ding et al. 1995; Lucy et al. 2000). In general, strains of CMV subgroup I are more virulent than those of subgroup $\mathrm{II}$, and the $2 \mathrm{~b}$ protein gene is a major determinant of viral virulence (Shi et al. 2002). The $2 \mathrm{~b}$ protein of subgroup I strains tends to have higher RSS activity than do the $2 b$ proteins of subgroup II strains (Ye et al. 2009). In general, the degree of symptom attenuation is positively correlated with reduced RNA silencing suppression activity. Kubota et al. (2003) reported that, in the case of a mild strain of TMV, L11, a single amino acid change within the 130-kDa protein accounts for the attenuation of its pathogenicity due to its reduced RNA silencing ability. Mutations within the HC-Pro gene of PPV, a member of the potyviruses, have been shown to be responsible for the differential ability of viral strains to suppress RNA silencing suppression and cause symptoms (González-Jara et al. 2005). Goto et al. (2007) reported that an attenuated CMV strain, CM95, had weaker RSS activity than that of its virulent revertant, and a key factor accounting for the noted difference in viral RNA silencing suppression was mapped to a single amino acid residue within the $2 \mathrm{~b}$ protein. These results suggest that the difference in pathogenicity between CMV-KT and CMV-Y used in the present study affected the difference in suppressor activity of these strains. On the other hand, Lin et al. (2007) showed that an attenuated strain of Zucchini yellow mosaic virus did not affect RNA silencing suppression, implying that symptom attenuation is not always correlated with reduced levels of RNA silencing suppression. The CMV-KT used in this work causes mild mosaic symptoms in N. tabacum or tomato, whereas CMV-TN did not induce any symptoms in these plants (Nomura et al. 2012). The present study also indicated that differences in the pathogenicity of the mild strains CMV-KT and CMV-TN did not simply correlate with the mutations we identified within the $2 \mathrm{~b}$ gene. As other genes and factors, such as $\mathrm{CP}$ genes and satellite RNAs, have been reported to also affect viral pathogenicity (Devic et al. 1989; Gonsalves et al. 1982; Shintaku et al. 1992; Suzuki et al. 1995), unknown factors other than base changes in the $2 \mathrm{~b}$ protein gene might account for the differences observed in viral symptoms caused by CMV-Y or CMV-KT (Lewsey et al. 2009).

RNA silencing is known to be strongly suppressed in apical tissue and newly emerged leaves after CMV infection (Béclin et al. 1998; Brigneti et al. 1998). In the present study, we observed that suppression of RNA silencing was induced mostly in the new developing leaves. Breakdown of TuMV resistance by CMV-KT must have occurred in the new, developing leaves because CMV-KT cannot suppress the RNA silencing machinery in such developing tissues before viral invasion. The presence of CMV was essential for the suppression of silenced sense transgenes in new leaves (Béclin et al. 1998). These results suggest that the breakdown of TuMV resistance by CMV-KT may be due to the viral movement and distribution after infection. Further analysis is required to reveal the differential infection dynamics of various plant-virus interactions in which mixed infections with mild or weakly pathogenic viral strains affect the development and severity of virusinduced symptoms.

Acknowledgments This work was partly supported by a grant from the Regional Research Promotion Project of the Ministry of Agriculture, Forestry and Fisheries of Japan. We thank Yoko Takahashi, Kiyoko Nakata, and Mitsuko Ogasawara for their technical assistance.

Open Access This article is distributed under the terms of the Creative Commons Attribution License which permits any use, distribution, and reproduction in any medium, provided the original author(s) and the source are credited.

\section{References}

Anandalakshmi R, Pruss GJ, Ge X, Marathe R, Mallory AC, Smith TH, Vance VB (1998) A viral suppressor of gene silencing in plants. Proc Natl Acad Sci USA 95:13079-13084

Béclin C, Berthomé R, Palauqui JC, Tepfer M, Vaucheret H (1998) Infection of tobacco or Arabidopsis plants by CMV counteracts systemic post-transcriptional silencing of nonviral (trans)genes. Virology 252:313-317

Brigneti G, Voinnet O, Li WX, Ji LH, Ding SW, Baulcombe DC (1998) Viral pathogenicity determinants are suppressors of transgene silencing in Nicotiana benthamiana. EMBO $\mathrm{J}$ 17:6739-6746

Devic M, Jaegle M, Baulcombe D (1989) Symptom production on tobacco and tomato is determined by two distinct domains of the satellite RNA of cucumber mosaic virus (strain Y). J Gen Virol 70:2765-2774

Ding SW, Anderson BJ, Haase HR, Symons RH (1994) New overlapping gene encoded by the cucumber mosaic virus genome. Virology 198:593-601

Ding SW, Li WX, Symons RH (1995) A novel naturally occurring hybrid gene encoded by a plant RNA virus facilitates long distance virus movement. EMBO J 14:5762-5772

Gonsalves D, Provvidenti R, Edwards MC (1982) Tomato white leaf: the relation of an apparent satellite RNA and cucumber mosaic virus. Phytopathology 72:1533-1538

González I, Martínez L, Rakitina DV, Lewsey MG, Atencio FA, Llave C, Kalinina NO, Carr JP, Palukaitis P, Canto T (2010) Cucumber mosaic virus $2 \mathrm{~b}$ protein subcellular targets and interactions: their significance to RNA silencing suppressor activity. Mol Plant Microbe Interact 23:294-303

González-Jara P, Atencio FA, Martínez-García B, Barajas D, Tenllado F, Díaz-Ruíz JR (2005) A single amino acid mutation in the Plum pox virus helper component-proteinase gene abolishes both synergistic and RNA silencing suppression activities. Phytopathology 95:894-901 
Goto K, Kobori T, Kosaka Y, Natsuaki T, Masuta C (2007) Characterization of silencing suppressor $2 \mathrm{~b}$ of cucumber mosaic virus based on examination of its small RNA-binding abilities. Plant Cell Physiol 48:1050-1060

Kubota K, Tsuda S, Tamai A, Meshi T (2003) Tomato mosaic virus replication protein suppresses virus-targeted posttranscriptional gene silencing. J Virol 77:11016-11026

Lewsey M, Surette M, Robertson FC, Ziebell H, Choi SH, Ryu KH, Canto T, Palukaitis P, Payne T, Walsh JA, Carr JP (2009) The role of the Cucumber mosaic virus $2 \mathrm{~b}$ protein in viral movement and symptom induction. Mol Plant Microbe Interact 22:642-654

Lin SS, Wu HW, Jan FJ, Hou RF, Yeh SD (2007) Modifications of the helper component-protease of Zucchini yellow mosaic virus for generation of attenuated mutants for cross protection against severe infection. Phytopathology 97:287-296

Lucy AP, Guo HS, Li WX, Ding SW (2000) Suppression of posttranscriptional gene silencing by a plant viral protein localized in the nucleus. EMBO J 7:1672-1680

Mitter N, Sulistyowati E, Dietzgen RG (2003) Cucumber mosaic virus infection transiently breaks dsRNA-induced transgenic immunity to Potato virus $Y$ in tobacco. Mol Plant Microbe Interact 16:936-944

Nomura K, Ohshima K, Anai T, Uekusa H, Kita N (2004) RNA silencing of the introduced coat protein gene of Turnip mosaic virus confers the broad-spectrum resistance in transgenic Arabidopsis. Phytopathology 94:730-736

Nomura K, Uekusa H, Kita N (2012) Characterization of cucumber mosaic virus isolated from tomato in Kanagawa Prefecture (In Japanese with English summary). Ann Rept Kanto Pl Prot Soc 59:43-45

Palukaitis P, García-Arenal F (2003) Cucumoviruses. Adv Virus Res 62:241-323

Roossinck MJ, Zhang L, Hellwald KH (1999) Rearrangements in the $5^{\prime}$ nontranslated region and phylogenetic analysis of cucumber mosaic virus RNA3 indicate radial evolution of three subgroups. J Virol 73:6752-6758

Sano Y, Kojima M (1989) Increase in cucumber mosaic virus concentration in Japanese radish plants co-infected with turnip mosaic virus. Ann Phytopath Soc Japan 55:296-302

Savenkov EI, Valkonen JPT (2001) Coat protein gene-mediated resistance to Potato virus $A$ in transgenic plants is suppressed following infection with another potyvirus. J Gen Virol 82:2275-2278

Shi BJ, Palukaitis P, Symons RH (2002) Differential virulence by strains of Cucumber mosaic virus is mediated by the $2 b$ gene. Mol Plant Microbe Interact 15:947-955
Shi BJ, Miller J, Symons RH, Palukaitis P (2003) The 2b protein of cucumoviruses has a role in promoting the cell-to-cell movement of pseudorecombinant viruses. Mol Plant Microbe Interact $16: 261-267$

Shintaku MH, Zhang L, Palukaitis P (1992) A single amino acid substitution in the coat protein of cucumber mosaic virus induces chlorosis in tobacco. Plant Cell 4:751-757

Siddiqui SA, Valkonen JPT, Rajamäki ML, Lehto K (2011) The 2b silencing suppressor of a mild strain of Cucumber mosaic virus alone is sufficient for synergistic interaction with Tobacco mosaic virus and induction of severe leaf malformation in $2 \mathrm{~b}-$ transgenic tobacco plants. Mol Plant Microbe Interact 24:685-693

Simón-Mateo C, López-Moya JJ, Guo HS, González E, García JA (2003) Suppressor activity of potyviral and cucumoviral infections in potyvirus-induced transgene silencing. J Gen Virol 84:2877-2883

Soards AJ, Murphy AM, Palukaitis P, Carr JP (2002) Virulence and differential local and systemic spread of Cucumber mosaic virus in tobacco are affected by the CMV $2 b$ protein. Mol Plant Microbe Interact 15:647-653

Suzuki M, Kuwata S, Kataoka J, Masuta C, Nitta N, Takanami Y (1991) Functional analysis of deletion mutants of cucumber mosaic virus RNA3 using an in vitro transcription system. Virology 183:106-113

Suzuki M, Kuwata S, Masuta C, Takanami Y (1995) Point mutations in the coat protein of cucumber mosaic virus affect symptom expression and virion accumulation in tobacco. J Gen Virol 76:1791-1799

Vargason JM, Szittya G, Burgyán J, Hall TMT (2003) Size selective recognition of siRNA by an RNA silencing suppressor. Cell 115:799-811

Voinnet O, Lederer C, Baulcombe DC (2000) A viral movement protein prevents spread of the gene silencing signal in Nicotiana benthamiana. Cell 103:157-167

Wang Y, Gaba V, Yang J, Palukaitis P, Gal-On A (2002) Characterization of synergy between Cucumber mosaic virus and potyviruses in cucurbit hosts. Phytopathology 92:51-58

Ye J, Qu J, Zhang JF, Geng YF, Fang RX (2009) A critical domain of the Cucumber mosaic virus $2 \mathrm{~b}$ protein for RNA silencing suppressor activity. FEBS Lett 583:101-106

Zhang X, Yuan YR, Pei Y, Lin SS, Tuschl T, Patel DJ, Chua NH (2006) Cucumber mosaic virus-encoded 2b suppressor inhibits Arabidopsis Argonaute1 cleavage activity to counter plant defense. Genes Dev 20:3255-3268 